\title{
Hysteroscopy: a boon in abnormal uterine bleeding
}

\author{
Grishma Kulkarni, Kunaal K. Shinde*, Mayur Thosar
}

Department of Obstetrics and Gynaecology, Post Graduate Institute Yashwantrao Chavan Memorial Hospital, Pimpri, Pune, Maharashtra, India

Received: 02 April 2019

Accepted: 06 May 2019

\section{*Correspondence:}

Dr. Kunaal K. Shinde,

E-mail: dr.kunaal.shinde@gmail.com

Copyright: ( $)$ the author(s), publisher and licensee Medip Academy. This is an open-access article distributed under the terms of the Creative Commons Attribution Non-Commercial License, which permits unrestricted non-commercial use, distribution, and reproduction in any medium, provided the original work is properly cited.

\section{ABSTRACT}

Background: Aim of the study was to analyze retrospectively the efficacy of hysteroscopy in the diagnosis of abnormal uterine bleeding (AUB).

Methods: Eighty-six women in the reproductive and perimenopausal age group (20-50 years) visiting the gynaecology OPD from March 2018 to February 2019 with the complaints of abnormal uterine bleeding were enrolled in the study. All the patients who underwent hysteroscopic examination were subjected to endometrial curettage; which was sent for histopathological examination (HPE). The hysteroscopic findings were then corelated and compared with HPE.

Results: Mean age of the patients was 37.2 years. Around $60.46 \%$ patients presented within six months of complaints. Clinically, $54.65 \%$ were diagnosed as menorrhagia, $37.2 \%$ as polymenorrhoea and $8.13 \%$ as intermenstrual bleeding. On hysteroscopy, $44.1 \%$ showed abnormal pathology. The positive findings including polyps $(8.13 \%)$, calcification $(3.48 \%)$, submucous myoma (12.79\%), necrotic mass and forgotten IUCD (2.32\%) and adhesions in one case. On the other hand, the findings of histopathology; 56 patients $(65.11 \%)$ had normal / proliferative / atrophic endometrium, 17 (19.76\%) had hyperplasia, $10(11.62 \%)$ had polyps and $3(3.48 \%)$ had calcified endometrium. There was no significant difference between two modalities for normal / proliferative / atrophic endometrium. The HPE diagnosed slightly higher patients of hyperplasia as compared to hysteroscopy. Hysteroscopy diagnosed a higher number of patients with submucous myoma and necrotic mass.

Conclusions: Hysteroscopy provided additional visual information for some pathologies which otherwise would remain undiagnosed by HPE.

Keywords: AUB, Hysteroscopy, Abnormal pathology, HPE

\section{INTRODUCTION}

Abnormal Uterine Bleeding is a common problem mainly encountered in peri-menopausal and post-menopausal women. It attributes for around $25 \%$ of total gynaecological surgeries performed by a gynaecologist. FIGO has classified AUB into 9 main categories, which are arranged according to the acronym PALM-COEIN (pronounced as 'pahm-koin'): polyp, adenomyosis, leiomyoma, malignancy and hyperplasia; coagulopathy, ovulatory dysfunction, endometrial, iatrogenic and not yet classified. In general, the components of the PALM group are discrete (structural) entities that can be measured visually with imaging techniques and/or histopathology, whereas the COEIN group is related to entities that are not defined by imaging or histopathology (non-structural). ${ }^{1} \quad$ Abnormal uterine bleeding has a negative impact on quality of life and in turn affects the efficiency of the women. ${ }^{2}$ It accounts for nearly $11 \%$ of total hysterectomies.

Management of AUB can be difficult without a proper diagnosis. Thorough history and physical examination can sometimes not lead us to a diagnosis. Dilatation and 
curettage is the conventional gold standard investigation employed in the evaluation. As it is an invasive procedure, the discomfort caused to the patient and the cost involved places a burden for its use as a screening tool. Also, it can have a diagnostic error ranging from 10$25 \%$.

There are other techniques such as trans-vaginal sonography (TVS), which in spite of being non-invasive, still remains as a prelimnary assessment tool which needs to be further reconfirmed with the use of more precise techniques. ${ }^{3-5}$

Hysteroscopy, however, is not a blind procedure unlike dilatation and curettage. It can also be used as an office procedure. Hysteroscopic evaluation allows direct visualization and assessment of the endocervical and uterine cavity, which proved to be a reliable method for diagnosing uterine abnormalities. ${ }^{6}$ Use of hysteroscopy in AUB is almost replacing blind curettage. This allows the abnormal area to be detected and then it can be subjected to curettage.

The present study tries to explore its potential as an office procedure in evaluation of abnormal uterine bleeding with histopathology as the basis for correlation.

\section{METHODS}

The present retrospective study analysis was conducted on 86 women attending the Gynaecology OPD at the Post Graduate Institute Yashwantrao Chavan Memorial Hospital, Pimpri -18 from March 2018 to February 2019.

\section{Inclusion criteria}

Women attending OPD in the reproductive (20-40 years) and peri-menopausal (>40 years) age group with complaints of abnormal uterine bleeding were included.

\section{Exclusion criteria}

Patients with pregnancy related bleeding, abortion, ectopic pregnancy, those with uterine and cervical infections and pelvic inflammatory diseases, those with STDs and vaginitis, lower genital tract malignancies, post-menopausal bleeding and those having medical contraindications to any invasive procedure were all excluded from the study.

The women were subjected to thorough physical examination and routine pre-op blood investigations (Hemoglobin, ABO\&Rh, Blood sugar, urine routine and microscopy) which was followed by hysteroscopy after obtaining post-counseling written informed consent. The procedure was done in minor operation theatre under sedation. All the procedures and measurements were noted down on the OR notes sheet as described by the Senior Faculty present in the OT. The procedure is done in the Minor OT room, with the patient placed in the lithotomy position. The patient is given short-acting general anesthesia by the anesthetist. Thorough bimanual examination is performed. Then, a Sims speculum is inserted to visualize the cervix and cervix is cleaned with $4 \%$ chlorhexidine solution. The cervix is then held with vulsellum, and the hysteroscope is inserted. Normal saline is used as the distension media and a $4 \mathrm{~mm} 30^{\circ}$ hysteroscope is used for the procedure. As the hysteroscope is introduced into the external os, the cervical canal and the internal os is noted. The first evaluation was done in panoramic view of the intrauterine cavity. Next, careful inspection of the lateral uterine walls, superior uterine cavity, and anterior and posterior uterine walls. Gentle movement of the hysteroscope was done during the procedure. Excessive trauma to the endometrial surface was avoided as it may cause bleeding which might obscure the view and has risk of perforation. Any pathology was inspected and documented. Biopsy/gross specimen was obtained (as the case may be) and subjected to histopathological evaluation. The statistics was calculated by calculating the percentage.

\section{RESULTS}

The age of the patients ranged from 20years to 50 years with a mean age of 37.2 years. Most of the patients had a history of symptoms for $<6$ months $(60.46 \%)$ while only $12.79 \%$ patients had symptoms $>1$ year. Clinically, majority of the patients presented with menorrhagia $(54.65 \%)$, followed by polymenorrhoea (37.2\%) and intermenstrual bleeding $(8.13 \%)$. Around $50 \%$ of the patients had slightly bulky uterus i.e. 6-8 weeks size, $31.39 \%$ had normal uterus and $18.6 \%$ had uterus size $>8$ weeks (Table 1).

On hysteroscopy, a maximum number of cases $(n=48$, $55.81 \%$ ) had no abnormal pathology ( 24 proliferative, 15 secretory and 9 atrophic). A total of $7(8.13 \%)$ cases were diagnosed to have polyp, $3(3.48 \%)$ had calcified endometrium, 11 (12.79\%) had submucous myoma, 2 $(2.32 \%)$ had necrotic mass, one had adhesions, and two had forgotten IUCD. However, on histopathology, 56 $(65.11 \%)$ cases had normal/proliferative/atrophic endometrium, $17(19.76 \%)$ had hyperplasia, $3(3.48 \%)$ had calcified endometrium, and $10(11.62 \%)$ had polyp. No significant difference between two modalities was observed with respect to number of normal/ proliferative/ atrophic endometrium. Histopathology diagnosed hyperplasia in significantly higher proportion of patients as compared to hysteroscopy. Hysteroscopy diagnosed significantly higher proportion of patients with submucous myoma and necrotic mass. Statistically, no significant difference between two modalities was observed with respect to other pathologies (Table 2).

Hysteroscopy provided additional information in 11 cases of sub mucous myoma, 2 cases of forgotten IUCD and necrotic mass each and one case of adhesions. Of the 11 cases of submucous myoma, 5 cases were diagnosed as 
hyperpasia, five cases as proliferative endometrium and one case as secretory endometrium. Three cases of cervical polyps were missed on hysteroscopy and five cases of hyperplasia. Overall there was $62.7 \%$ agreement between histopathology and hysteroscopy.

Table 1: Patient demographic profile and other characteristics.

\begin{tabular}{|c|c|c|}
\hline $\begin{array}{l}\text { Sr. } \\
\text { No. }\end{array}$ & Characteristics & Statistics (\%) \\
\hline 1. & Mean age & 37.2 \\
\hline \multirow{4}{*}{2.} & Duration of symptoms & \\
\hline & $<6$ months & $52(60.46)$ \\
\hline & 6 months -1 year & $23(26.74)$ \\
\hline & $>1$ year & $11(12.79)$ \\
\hline \multirow{4}{*}{3.} & Clinical presentation & \\
\hline & Menorrhagia & $47(54.65)$ \\
\hline & Polymenorrhoea & $32(37.2)$ \\
\hline & Intermenstrual bleeding & $7(8.13)$ \\
\hline \multirow{4}{*}{4.} & Uterus size & \\
\hline & Normal & $27(31.39)$ \\
\hline & 6-8 weeks & $43(50)$ \\
\hline & $>8$ weeks & $16(18.60)$ \\
\hline
\end{tabular}

Table 2: Comparison of hysteroscopic and histopathological abnormalities.

\begin{tabular}{|c|c|c|c|}
\hline $\begin{array}{l}\text { Sr. } \\
\text { No. }\end{array}$ & Findings & $\begin{array}{l}\text { Hysteroscopy } \\
(\%)\end{array}$ & $\begin{array}{l}\text { Histopathology } \\
(\%)\end{array}$ \\
\hline \multirow{4}{*}{1.} & Hormonal & $48(55.81)$ & $56(65.11)$ \\
\hline & Proliferative & $24(27.9)$ & $29(33.72)$ \\
\hline & Secretory & $15(17.44)$ & $17(19.76)$ \\
\hline & Atrophic & $9(10.46)$ & $10(11.62)$ \\
\hline 2. & Hyperplasia & $12(13.96)$ & $17(19.76)$ \\
\hline \multirow{3}{*}{3.} & Polyp & $7(8.13)$ & $10(11.62)$ \\
\hline & Endometrial & $5(5.81)$ & $5(5.81)$ \\
\hline & Cervical & $2(2.32)$ & $5(5.81)$ \\
\hline 4. & $\begin{array}{l}\text { Submucous } \\
\text { myoma }\end{array}$ & $11(12.79)$ & 0 \\
\hline 5. & Calcified & $3(3.48)$ & $3(3.48)$ \\
\hline 6. & $\begin{array}{l}\text { Forgotten } \\
\text { IUCD }\end{array}$ & $2(2.32)$ & 0 \\
\hline 7. & Adhesion & $1(1.16)$ & 0 \\
\hline 8. & $\begin{array}{l}\text { Necrotic } \\
\text { mass }\end{array}$ & $2(2.32)$ & 0 \\
\hline
\end{tabular}

\section{DISCUSSION}

In the present study, hysteroscopy showed the absence of any abnormal pathology in slightly more than half $(55.81 \%)$ of the patients. Among these 24 were proliferative phase, 15 were in secretory phase and rest of the 9 were atrophic. Hysteroscopically diagnosed abnormal pathology rates have been shown to vary substantially across different series. In a study, Mukhopadhyay and Ashis reported it to be $32.6 \%$. $^{7}$
Similar to present study, Katke and Zakariya reported pathological abnormalities in $51.6 \%$ of their patients, whereas Guin et al reported them in $56 \%$ of their patients. $^{8,9}$ However, the differences in prevalence of hysteroscopically diagnosed pathologies might be incidental and might vary from series to series.

Abnormal pathology was found in $40.69 \%$ of cases excluding calcification in the present study. Among different abnormal pathologies diagnosed by hysteroscopy, 6/18 previous studies $(33.3 \%)$ reported polyps to be the diagnosis while $9 / 18(50 \%)$ reported hyperplasia to be the most common abnormal pathologies. In our study, endometrial hyperplasia $(13.95 \%)$ was the most common abnormal pathology, which was followed by endometrial polyps (5.81\%), cervical polyp, necrotic mass and forgotten IUCD in $2.32 \%$ and adhesions in one case. Although in present study, no case of endometrial carcinoma was diagnosed, a sizeable number of cases $(7.1 \%)$ were diagnosed to have necrotic mass reflective of a progression towards malignancy ${ }^{10}$. These findings are in accordance with the observations of a number of other studies that did not report a single case of endometrial carcinoma in their series. Endometrial cancer is a rare finding in AUB cases with only few studies reporting its prevalence in the range of $1.7-4.1 \% .^{11,12}$

In present study, on histopathology, 56 (65.11\%) cases were shown to have normal/proliferative/atrophic endometrium, 17 (19.76\%) had hyperplasia, 3 (3.48\%) had calcified endometrium, and $10(11.62 \%)$ had polyp. Similarly, Patil et al. ${ }^{13}$ also showed the absence of abnormal pathologies in $67 \%$ of their patients. In their study, they reported hyperplasia with and without atypia (16\%), complex hyperplasia with and without atypia (4\%), endometrial/fibroid polyps $(6 \%)$ and endometrial cancer $(2 \%)$ as the major pathologies involved. Valson et $\mathrm{al}^{14}$ in their study also reported normal/atrophic findings in $72 \%$ of their patients of AUB and reported simple hyperplasia with/without atypia (12\%), polyp (8\%), submucous myoma $(2 \%)$ and endometrial cancer $(2 \%)$ as the major abnormal pathologies involved. In contrast, Katke and Zawariya found abnormal pathologies in only $5 / 66(7.6 \%)$ of their patients - 4 having simple hyperplasia with/ without atypia and 1 (1.5\%) showing abnormal shedding. ${ }^{8}$ A low prevalence of histopathological abnormalities was also reported by Sunitha and Somlatha ${ }^{15}$ who reported $68 \%$ of their cases to have a normal/atrophic endometrium and found endometrial hyperplasia as the most common abnormal pathology involved $(20 \%)$ and did not find any case of endometrial cancer. Dinic' et al also found abnormal pathologies in majority of their cases $(50.63 \%)$ and found endometrial polyp (21.8\%), cervical polyp (13.2\%) and hyperplasia $(6.83 \%)$ as the major abnormal pathologies and endometrial cancer in $1.28 \%$ of their cases. ${ }^{16}$ The findings of present study are thus more proximal to the results of Patil et al and Sunitha and Somlatha who 
reported abnormal pathologies in less than half of patients in their series. ${ }^{13,15}$

As far as detection rate of different abnormal pathologies was concerned, the present study did not show a significant difference between hysteroscopic and histopathological findings for almost all the hysteroscopic findings except for detection rate of hyperplasia, submucous myoma and necrotic mass. In the present study, hysteroscopy had a significantly lower detection rate for hyperplasia (13.95\%) as compared to HPE $(19.76 \%)$; while hysteroscopy showed a higher detection rate for submucous myoma (12.79\%) and necrotic masses $(2.32 \%)$ as compared to HPE (nil in both) as blind D\&C may miss both these findings.

One of the limitations of present study was its sample size. However, the study was able to explain the usefulness of hysteroscopy in evaluation of gross structural and anatomical pathologies responsible for AUB. Another limitation was the absence of any malignant lesion and hence our inability to evaluate the efficacy of hysteroscopy for this specific and most important diagnosis. Further studies on larger sample size are recommended.

\section{CONCLUSION}

The findings of the study suggested that hysteroscopy was quite useful in diagnostic workup of abnormal uterine bleeding. Although it had an agreement with histopathology to the extent of $62.9 \%$ only, it provided additional information for pathologies that remained undiagnosed on histopathology, viz. submucous fibroid, adhesion and necrotic mass (although the reason for missing these findings may have been blind dilatation and curettage). Keeping in view the additional information provided by hysteroscopy, it is essential that it should be made essential part of diagnostic workup of cases of abnormal uterine bleeding.

Funding: No funding sources Conflict of interest: None declared

Ethical approval: The study was approved by the Institutional Ethics Committee

\section{REFERENCES}

1. Munro MG, Critchley HO, Broder MS, Fraser IS. FIGO classification system (PALM-COEIN) for causes of abnormal uterine bleeding in nongravid women of reproductive age. Int $\mathbf{J}$ Gynecol Obstet. 2011;113:3-13.

2. Frick KD, Clark MA, Steinbach's DM, Langenberg P, Stovall D, Munro MG, Dickersin K, STOP-DUB Research Group. Financial and quality-of-life burden of dysfunctional uterine bleeding among women agreeing to obtain surgical treatment. Women's Health Issues. 2009;19(1):70-8.
3. Veena BT, Shivalingaiah N. Role of transvaginal sonography and diagnostic hysteroscopy in abnormal uterine bleeding. J Clin Diagn Res JCDR. 2014;8(12):OC06-8.

4. Jain M, Kanhere A, Jain AK. Abnormal uterine bleeding: a critical analysis of two diagnostic methods. Int J Reprod Contracept Obstet Gynecol. 2014;3(1):48-53.

5. Goyal BK, Gaur I, Sharma S, Saha A, Das NK. Transvaginal sonography versus hysteroscopy in evaluation of abnormal uterine bleeding. Med $\mathbf{J}$ Armed Forces India. 2015;71(2):120-5.

6. Razzes A, Shankar-ud-Din S, Soomro N. Role of diagnostic hysteroscopy in case of abnormal uterine bleeding. Pak J Surg. 2011;27(4):309-15.

7. Mukhopadhyay SR, Ashis K. Correlation between diagnostic hysteroscopy and its histopathological examination in the evaluation of abnormal uterine bleeding. Indian J Prev Soc Med. 2015;45(1-2):62-5.

8. Katke RD, Zarariya AN. Use of diagnostic hysteroscopy in abnormal uterine bleeding in perimenopausal age group and its clinicopathological co-relation with ultrasound and histopathology findings: experience in a tertiary care institute. Int $\mathbf{J}$ Reprod Contracept Obstet Gynecol. 2015;4(2):413-8.

9. Guin G, Sandhu SK, Lele A, Khare S. Hysteroscopy in evaluation of abnormal uterine bleeding. J Obstet Gynaecol India. 2011;61(5):546-9.

10. Bredholt G, Mannelqvist M, Stefansson IM, Birkeland E, Bø TH, Øyan AM et al. Tumor necrosis is an important hallmark of aggressive endometrial cancer and associates with hypoxia, angiogenesis and inflammation responses. Oncotarget. 2015;6(37):39676-91.

11. Nandan N, Manjeera L, Rai S, Gowri M. Diagnostic hysteroscopy in abnormal uterine bleeding and it's histopathologic correlation: our experience. NUJHS. 2013;3(2):13-7.

12. Singh S, Taneja BK, Singh P, Ahlawat R. Role of diagnostic hysteroscopy in abnormal uterine bleeding. Int J Reprod Contracept Obstet Gynecol. 2014;3(3):544-51.

13. Patil SG, Bhute SB, Inamdar SA, Acharya NS, Shrivastava DS. Role of diagnostic hysteroscopy in abnormal uterine bleeding and its histopathologic correlation. J Gynecol Endosc Surg. 2009;1(2):98104.

14. Valson H, Kulkarni C, Mukerjee S, Gowda SN. The role of diagnostic hysteroscopy in abnormal uterine bleeding and its histopathological correlation following blind dilatation and curettage. Int J Reprod Contracept Obstet Gynecol. 2016;5(3):609-14.

15. Sunitha $\mathrm{C}$, Somalatha R. Clinical study of diagnostic hysteroscopy in abnormal uterine bleeding and its histopathological correlation. IOSR J Dent Med Sci. 2013;5(3):43-6.

16. Dinic' SPT, Kopitovic' V, Antic' V, Stamenović S, Mitić D, Milošević J. Role of hysteroscopy in evaluation of patients with abnormal uterine 
bleeding. Acta Facultatis Medicae Naissensis. 2011;28(3):177-81.
Cite this article as: Kulkarni G, Shinde KK, Thosar M. Hysteroscopy: a boon in abnormal uterine bleeding. Int J Reprod Contracept Obstet Gynecol 2019;8:2410-4. 